\title{
Subjetividades lesbianas en los espacios no inscritos de la identidad
}

\section{Lesbian Subjectivities in the Blank Spaces of Identity}

\author{
Lucía Guerra \\ Departamento de Español y Portugués, Universidad de California, Irvine, Estados \\ Unidos \\ Icunning@uci.edu
}

Resumen - En el presente ensayo se analiza la identidad lesbiana dentro del contexto cultural que la ha hecho sinónimo de lo ininteligible e innombrable, convirtiéndola en un espacio en blanco, sin la posibilidad de crear un contradiscurso. La invisibilidad cultural del lesbianismo ha sido exacerbada por la supremacía del espacio privado de la casa asignado a la mujer y el acceso minoritario a la producción cultural, hechos que han cancelado la posibilidad de una genealogía y subcultura propias. Los textos aquí comentados inscriben en ese espacio en blanco un imaginario de la sexualidad lesbiana y discursos que dibujan trazos de la identidad silenciada. Así, en En breve cárcel (1981) de Sylvia Molloy y El cielo dividido (1996) de Reina Roffé, la experiencia amorosa es el puente que conduce a una reflexión acerca de la identidad, mientras en Tu nombre escrito en el agua (1995) de Irene González Frei, deseo e identidad se entrelazan en una relación no-disyuntiva que cancela los paradigmas del falogocentrismo.

Palabras clave: inscripción de la identidad, sexualidad lesbiana, imaginario erótico.

Abstract • In this essay, lesbian identity is analyzed within a cultural context which has made of lesbianism a synonym of the unnameable and inintelligible, thus inscribing a blank space and eliminating the possibility of a counter-discourse. The cultural invisibility of lesbianism has been incremented by the primacy of private space and the limited access to cultural production, two facts that have cancelled the creation of a specific genealogy and sub-culture. The novels here discussed inscribe within that blank space, an imaginary of lesbian sexuality in a discourse that traces a silenced identity. Both in En breve cárcel (1981) by Sylvia Molloy and El cielo dividido (1996) by Reina Roffé, erotic experiences are the bridge to a reflexion on lesbian identity while in Tu nombre escrito en el agua (1996) by Irene González Frei, Desire and Identity are intertwined in a reciprocal relation that cancels the paradigms of phalogocentrism.

Key words: inscribing identity, lesbian sexuality, erotic imaginaries. 


\section{LA INVISIBILIDAD CULTURAL DEL LESBIANISMO}

Las prácticas sexuales lesbianas han estado marcadas por el silencio y la invisibilidad de lo oculto y prohibido, aunque, a la vez, el espacio privado de la casa asignado a la mujer ha facilitado una cierta impunidad reforzada por la noción patriarcal de "lo femenino", que explica y acepta las relaciones afectivas entre dos mujeres como algo «normal». A la brutalidad o tinte jocoso de los múltiples vocablos para designar al homosexual expuesto por su rol masculino a los espacio públicos, se opone un número muy reducido de palabras para nombrar a la mujer que tiene relaciones sexuales con otras mujeres (tribadista, safista, marimacho, tortillera, bollera). Limitación del lenguaje que señala, en el fondo, un eludir que tiñe incluso la palabra «lesbiana», acuñada a fines del siglo XIX y asociada a un cultismo de élite letrada (Lesbos, una pequeña isla ubicada en el mar Egeo donde hace más de dos milenios, escribió la poeta griega Safo).

El rol primario asignado a la mujer en el espacio privado de la casa y fuera de los centros productores de cultura obviamente contribuyó no sólo a la invisibilidad de la sexualidad lesbiana, sino también a la carencia de datos históricos o la creación de una genealogía cultural. Las expresiones públicas de la sexualidad gay han, por el contrario, configurado un vasto archivo de datos históricos, mientras que la participación casi exclusiva de los hombres en las producciones culturales facilitó la creación de una subcultura.

Mientras la mera sospecha de relaciones sexuales entre dos hombres constituía un pecado escandaloso que merecía incluso la hoguera, según leyes de los Reyes Católicos, las relaciones entre mujeres eran generalmente despojadas de toda posible sexualidad y trasladadas al plano de "los afectos femeninos", dentro de un imaginario androcéntrico en el cual los hombres se consideraban los únicos poseedores del deseo sexual.

En la historia discontinua, llena de silencios y vacíos, con respecto a las relaciones lesbianas, son sólo visibles aquéllas correspondientes a mujeres de un cierto rango social en Europa o Estados Unidos que extendían, además, lazos de carácter intelectual. Tal es el caso, por ejemplo, de las Sofistas de la reina María Antonieta y las Preciosas de Madelene de Scudery en Francia del siglo XVIII, el Círculo de Dublín de Frances Brudenell, también en el siglo XVIII, y los matrimonios bostonianos en el siglo XIX. Tanto estas relaciones como las conocidas hacia la década de los veinte fueron interpretadas con una cierta condescendencia patriarcal, como casos curiosos, divertidos e inofensivos (Wolfe, 301-324).

Como señala Judith Butler, la ausencia de una prohibición y castigo para las prácticas lesbianas corresponde a un tipo de discriminación que las relega al ámbito de lo invisible e inimaginable, a aquello omitido y borrado de los discursos oficiales y, por lo tanto, sin la posibilidad de elaborar un contradiscurso. Butler afirma:

Here oppresion works through the production of a domain of unthinkability and unnameability. Lesbianism is not explicitly prohibited in part because it has not even made its way into the thinkable, the imaginable, that grid of cultural intelligibility that regulates the real and the nameable, how, then, to «be» a lesbian in a political context in which the lesbian does not exist? That is, in a political discourse that wages its violence against lesbianism by discourse itself? To be prohibited explicitly is to occupy a discursive site from which something like a reverse-discourse can be articulated; to be implicitly proscribed is not even to qualify as an object of prohibition (312). 
No ser inteligible a nivel de lo nombrado, lo concebible y lo imaginable hizo de la sexualidad lesbiana un espacio en blanco condenado al silencio y la invisibilidad. Hecho que debe comprenderse en el contexto de una cultura de Occidente en la cual el deseo, desde El simposio de Platón, se plantea como una carencia del sujeto masculino que busca su complemento generalmente en «lo femenino» dentro de una estructura heterosexual y binarizada, concepto que se exacerba en la teoría de Freud, quien define el deseo como inherentemente masculino (Grosz, 67-84). Por lo tanto, resulta inconcebible que la mujer (objeto pasivo del deseo) sea un sujeto deseante y agente de un acto sexual totalmente fuera de esa dicotomía genérica adscrita a la sexualidad, como un hacer escindido entre «lo masculino» $\mathrm{y}$ «lo femenino», dentro de la oposición binaria de «lo activo» y «lo pasivo».

Ininteligibilidad cultural que a nivel de la experiencia lesbiana misma se reitera por la carencia de un discurso y un imaginario, debido a la escasa participación que tuvieron las mujeres en la producción cultural y al aislamiento de las lesbianas en un ámbito privado, que impidió el sentido de comunidad y la creación de cartografías secretas. Es más, la falta de comunicación entre ellas y el hecho de no "ser dichas» por los discursos heterosexuales mayoritarios impidieron la articulación de una figura identitaria anclada en una historia y genealogía propias.

En el caso específico de Latinoamérica, la exclusión ha sido aun mayor que en Europa o Estados Unidos, y en antologías y estudios críticos recientes desde la perspectiva de la crítica queer se hace evidente la abismante mayoría de textos escritos por autores gay. Es más, en el caso de escritoras que lograron un reconocimiento público, tales como Teresa de la Parra y Gabriela Mistral, la experiencia lesbiana se mantuvo en estricto silencio y sólo se aludió a ella en una escritura tangencial o a nivel de un subtexto que sólo ahora se empieza a descifrar.

Por consiguiente, recién en la década de los setenta la experiencia lesbiana empieza a aparecer de manera explícita en la narrativa latinoamericana. La única excepción es Cárcel de mujeres (1956), texto de carácter testimonial de María Carolina Geel, escritora chilena que causó un gran escándalo al disparar y matar a su amante en el Hotel Crillón, lugar de reunión de la élite santiaguina de la época. Geel fue sentenciada a tres años y un día por su crimen, y a partir de sus vivencias en la cárcel escribió este texto híbrido, en el cual se entrelaza lo visto u oído por ella en el entorno carcelario con una reflexión filosófica, a través de la cual intenta redimir su delito.

Por esta razón, la voz narrativa se escinde entre un yo testimonial que describe lo que oye o ve y un yo introspectivo que trata de explicar las causas de su crimen a un nivel metafísico. En el espacio de la cárcel, esta subjetividad letrada se enfrenta con un mundo donde se astilla la noción normativa de «lo femenino». Las presas, provenientes de los sectores bajos de la sociedad chilena, son mujeres de fuerza física y lenguaje procaz, en ellas prima la violencia y matar y robar son los únicos recursos para sobrevivir. Desde el sector del Pensionado, reservado a reclusas que pueden pagar por ciertos privilegios, llegan hasta ella las voces y ruidos del Patio de las Guaguas, el Patio por Días, el Proceso y el Pabellón de las Condenadas. Frente a ese entorno, Geel asume su posición de receptora intelectual y burguesa para censurar a las presas de clase social inferior. Sin embargo, esta perspectiva es socavada por las experiencias mismas, generando una contradicción entre lo visto u oído y el reciclaje letrado que realiza el yo testigo. Así, al referirse a María López narra lo siguiente: 
Ella de pronto llama a alguna y le prodiga adjetivos en extremo tiernos. En su voz, que parece formarse en un punto preciso entre su nariz y su garganta, vibra, salaz, una secreta alegría, y entonces de un modo inequívoco uno percibe que es lesbiana. Se piensa enseguida, con un cierto terror, que su sexualidad así dirigida debe tener expresiones casi bárbaras (25).

A lo experiencial percibido como «alegría del amor» se yuxtapone «lo bárbaro», en un interpretar que concuerda con el discurso letrado de ideología heterosexual. Así, el yo letrado califica el lesbianismo como «desvío» (35), como «sibilinos oficios de un amor pagano» (36) y «el extraño sentimiento cuyo prohibido hechizo ardiera en los cantos de Bilitis» (36). Sin embargo, aquellas mujeres que ella califica como «ambidextras» (51) dan evidencia del amor profundo al hacerse un tajo en la mano para realizar un pacto de sangre en su relación, mientras María Patas Verdes intercambia apasionadas cartas con Fresia en el Pabellón de las Condenadas y Adelaida, al salir libre, no tolera estar lejos de su amada y comete un crimen horrendo sólo para volver a estar con ella en la cárcel.

Si en la cultura heteronormativa los vocablos utilizados por el yo letrado corresponden a aquéllos que nombran el lesbianismo, en Cárcel de mujeres se cancela dicha relación denotativa, creando una disyunción significativa, puesto que las experiencias amorosas no corresponden a ese discurso cargado de prejuicios y cultismos. Por el contrario, estas historias de amor hacen reflexionar al yo testigo, que no ve ninguna diferencia entre ese amor catalogado como ilícito y el amor heterosexual, "Ese amor misterioso, al parecer tan lleno él de sombras y desesperanzas como el otro» (44).

Este concepto ya había sido inscrito varios años antes por María Carolina Geel en su novela El mundo dormido de Yenia (1946), donde Loreta despierta en la protagonista el deseo sexual:

Era una muchacha alta, muy bella y un tanto maciza [...] La conversación varió y pasado un momento me pareció que continuaba en mi cintura, patente, la presión de las manos de la muchacha. La miré sorprendida. Sus ojos azules se encontraron con los míos, y al choque, se produjo una chispa que me era desconocida. Desvié la vista y por largo tiempo me quedé desconcertada, casi humillada, sin saber si debía mirarla nuevamente, cosa que deseaba fuertemente y no quería en absoluto por presentir en ello un mundo algo tortuoso (92).

En esta ambivalencia que se incrementa en Cárcel de mujeres por tratarse de la proyección autobiográfica de una imagen pública, el desear de Yenia incluso la induce a reunirse con Loreta en su dormitorio para constatar los sentimientos de la joven lesbiana, y aunque finalmente opta por el amor heterosexual, las páginas de este episodio inscriben y legitiman el deseo lesbiano, planteado en la novela como una alternativa más en la vida amorosa de Yenia.

\section{LOS ESPACIOS DEL DESEO Y LA CONFIGURACIÓN IDENTITARIA}

En 1976 se publica en Argentina Monte de Venus, novela que cuenta la trayectoria de Julia, una joven lesbiana que huye de su pueblo a Buenos Aires para poder vivir libremente su amor con Elsa. Como indica su autora Reina Roffé: «[...] a los pocos días de editado, el libro cayó en la mira de la censura que, de un solo plumazo, firmó la prohibición por 
inmoralidad y lo retiró de circulación» (La rompiente, 10). Esta decisión se debió en parte al hecho de que, a través de las peripecias de una mujer y no del típico personaje masculino, se muestra la pobreza de los arrabales de Buenos Aires y una escuela nocturna que alegoriza la corrupción de la nación argentina y el fraude que representó el regreso de Perón. Pero la verdadera inmoralidad radicaba en las prácticas lesbianas y la vida delictual de Julia, que ponían a la luz un tipo de sexualidad mantenida a nivel de lo prohibido y culturalmente ininteligible. Además Julia, en su constante merodear por las calles para "ganarse el mango callejeando"(Monte de Venus, 122), no sólo transgrede el espacio doméstico asignado a la mujer sino que también usurpa los roles primarios del hombre, al ser agente tanto de la obtención del sustento diario como de sus relaciones sexuales.

En Monte de Venus, como en novelas lesbianas posteriores, se observa una escisión entre la identidad asignada a partir de una anatomía femenina y esa otra identidad mantenida en secreto. La casa se divide, así, en el espacio colectivo de la restricción heterosexual y en ese otro espacio de rincones y puertas cerradas, donde el yo deseante, de manera íntima y secreta, incursiona en su sexualidad. De esta manera, la casa es también albergue de un deseo ilícito que los otros vigilan y acechan (Réquiem por una muñeca rota, 2000, de Eve Gil, Una mujer y otras cuatro, 2004, de Mireya Robles). Cuartos cerrados o rincones oscuros susceptibles de una sospecha que, al ser constatada, genera el castigo y el repudio del resto de la familia. Si para la perspectiva filosófica de Humberto Giannini, el hogar es el espacio de un sí mismo que se libera de las imposiciones de lo otro y los otros, para el yo lesbiano la casa familiar es el espacio de la represión, de un código social que satura al sí mismo de lo ajeno: «Mis años de soledad, sintiéndome un hongo extraño y diferente a cuanta mujer conocía [...] Yo, la rara. La desadaptada en silencio. La que nunca entendió por qué no era como las demás» (Roffiel, 41). No ser como las demás implica no compartir las metas del matrimonio y la maternidad, verdaderos fundamentos de un sistema heterosexual que organiza sus construcciones culturales de "lo femenino» en torno a la subordinación y dependencia con respecto al hombre.

De manera disidente, el deseo lesbiano sugiere otras topografías del cuerpo, otras coreografías eróticas que hasta hace muy pocos años correspondían a lo silenciado. Fuera de toda inscripción legible, ese cuerpo lesbiano que anatómicamente corresponde al de una mujer, es también el cuerpo de una subjetividad que no se identifica plenamente con la vasta fabricación patriarcal del signo «mujer» y elude el régimen de la heterosexualidad obligatoria (Wittig, 103-108). Esta evasión, como acto de resistencia, es el único trazo sólido de una identidad que está fuera de todo campo discursivo legítimo.

La sexualidad vivida en el espacio cerrado de la casa y dentro de una cultura que la ha relegado a ser un espacio en blanco cancela, para la identidad lesbiana, toda posibilidad de conexiones comunitarias y el acceso a una definición de su identidad propia en los márgenes de una identidad adscrita, que también impide un proceso identitario para las mujeres heterosexuales. Así lo señala Adrienne Rich: "The lesbian trapped in the «closet, the woman imprisoned in prescriptive ideas of the normal share the pain of blocked options, broken connections, lost access to self-definition freely and powerfully assumed» (35).

En este sentido, En breve cárcel (1981) de Sylvia Molloy, marca un hito importante, al presentar una reapropiación del espacio de la casa para convertirlo en sitio de la escritura y la búsqueda de una noción de identidad. El regreso de la protagonista al mismo departamento donde vivió sus relaciones amorosas con Vera y Renata prefigura una instancia 
diferente, que transforma lo que fue espacio de la sexualidad ilícita en «cuarto propio» de la escritura de un yo, quien a través de la memoria, los sueños y trazos ficcionales logra encontrar una definición provisoria para su propia identidad. Lejos entonces de ser ese espacio cerrado que metaforiza la represión, exclusión e ininteligibilidad de la experiencia lesbiana, en esta novela, el cuarto donde escribe la protagonista deviene en espacio de una productividad cultural que inscribe y legitima al sujeto lesbiano.

Para esa subjetividad que escribe mientras espera la llegada de Renata, el espacio del departamento conjuga pasado y presente. Aquel pasado donde tuvo su primera cita con Vera y vivió tanto la ilusión del amor como la humillación de haber oído hasta el más mínimo detalle del acto sexual entre Vera y Renata, triángulo amoroso que se modifica cuando, tras el abandono de Vera, ella inicia una relación con Renata, quien posteriormente la abandona. Si en el pasado ése fue el espacio de la pasión, ahora es el espacio de la introspección y la memoria, de una escritura que se nutre de "lo vivido", pero también de «lo soñado» y «lo fabulado». Simultaneidad de lo que fue y lo que está ocurriendo en un presente que modifica no sólo sus sentimientos hacia Vera y Renata, sino también ese flujo del yo que va descartando y rearmando elementos de sí misma. Cristina FerreiraPinto comenta: «El cuarto es un espacio ambiguo por varios motivos. Aunque esté bien delimitado, no sólo por sus paredes sino, principalmente, por los objetos que la protagonista dispuso a su alrededor», el cuarto «nunca llegó a ser un lugar fijo» (45). En él, la protagonista va en dos direcciones opuestas: hacia sí misma y hacia el Otro (Vera, Renata, la infancia). El cuarto pertenece a los dos —el sujeto y el otro-, "guarda referencias de los dos» (77). Esta ambivalencia hace también de ese cuarto la prisión del amor y la celda de la reflexión y la escritura como praxis liberadora.

La protagonista empieza a escribir con la intención de «transcribir con saña, una realidad vivida» (Molloy, 19). Ésa que fue una realidad teñida de celos y resentimientos ahora produce un deseo de venganza que se realizará a través de la escritura como acto de exorcismo. Su intención es escribir los itinerarios que Vera y Renata dejaron como huella en su propia existencia, sin embargo, empieza a escribir fragmentos de su infancia, sueños que desde el inconsciente envían señales: "Volvió a esta ciudad para escribir pero no para escribir lo que está escribiendo» (68). De esta manera, la escritura planeada da paso a un flujo de la subjetividad que será tachado y modificado posteriormente por ese yo en otra instancia, en la cual asume la función de revisar y editar lo escrito, ahora ya no simplemente la expresión de lo que pensaba y sentía en el momento de escribir, sino un texto que, al ser releído, la transcribe, la encuadra como una prisión que al mismo tiempo se convierte en refugio. "Las líneas que escribe, que ayer fueron estallido, hoy son, de nuevo, refugio y prisión. Las cuatro paredes que ayer se derrumbaron hoy se han vuelto a recomponer alrededor de la espera y el recuerdo» (71).

El «cuarto propio» de la escritura, en una rearticulación del espacio, ahora no sólo se presenta como entorno material sino también como alusión a ese texto que es también territorio en el cual los deslindes se hacen difusos y siempre cambiantes por su textura porosa:

Para descifrar lo que ella fue y lo que sigue siendo, para que estallen estas cuatro paredes en las que ha proyectado con indiscreción sus nostalgias y que se han tragado implacablemente sus recuerdos. Paredes porosas y altaneras, ahora sólo le devuelven —ahora que está sola- la pretenciosa textura del género oscuro, viejo y sucio, que ha cumplido su función: paredes mudas y ahítas, donde ha escrito todo, y que pronto habrá que despellejar (121-122). 
La escritura es también cuerpo, tanto en el sentido de corpus (inscripción material de la letra que se convierte en objeto susceptible de ser analizado) como de ese cuerpo narrante que ha sufrido otras inscripciones:

¿Cómo acatar las prohibiciones del recuerdo cuando está ante sus manos y dentro de un cuerpo que le devuelve, como un manuscrito desmañado, corregido y lleno de tachaduras, lo que en él ha inscrito? Podrá modificarlo, decirse que lo modifica, pero bajo lo que añada y lo que tacha persistirá la letra primera que no consigue anular (111).

Y será el suceso del cuerpo enfermo el que permitirá a ese cuerpo despojarse de las inscripciones culturales para volver a ser el recinto de lo básico y primigenio, fuera de las culturizaciones que lo revisten: «[...] quiso sólo sentirse y reconocerse entera en el cuerpo pesado e inerte que, en cuanto lo atendió, empezó a dolerle menos: quiso instalarse plenamente en esa masa como quien se instala por fin en un domicilio al que no creía tener derecho y que, desde siempre, le había pertenecido" (107).

La recuperación del cuerpo como origen y lo único realmente poseído marca el umbral de la reflexión acerca de la identidad representada por el cuerpo mitológico de dos mujeres: Diana y Artemisa. En un sueño la protagonista ve a su padre, quien le indica que debe ir a Éfeso a buscar a Artemisa, diosa de la fecundidad simbolizada por sus senos abundantes. Sin embargo, a ella la atrae su contrafigura Diana, la cazadora de pechos pequeños y firmes siempre frente a algún desafío. La indicación del padre implica buscar la identidad en la esfera de una heterosexualidad obligatoria, que hace de la maternidad en la mujer una "esencia» identitaria basada en rasgos biológicos que, a través de un procesamiento cultural, convierte lo biológico en base de lo ontológico. Es precisamente debido a lo maternal como «esencia» de la identidad que la estructura patriarcal asignó a la mujer el espacio cerrado de la casa.

Mientras ha estado escribiendo su texto, la protagonista ha vuelto a encontrarse con Vera y Renata, descubriendo que ambas son diferentes a lo que ella creyó y quiso escribir con la intención de una venganza. Por consiguiente, el tópico renacentista de la cárcel de amor sufre una fisura, abriendo lo que fue un espacio hermético y opresor. De allí que uno de los epígrafes de la novela sea el poema de Quevedo «Retrato de Lisi que traía en una sortija», donde la cárcel y el sufrimiento del prisionero bajo la voluntad de la belle sans merci se hace breve. Más importante aún, en este poema se trata de un retrato y no de la amada misma, de una versión representacional que, como tal, es sólo una imagen susceptible de distorsiones con respecto al sujeto representado. En Vera descubre la artificialidad de su performance, que es solamente una fachada, mientras se da cuenta de que a Renata la amará siempre, aunque ella esté teniendo otra relación amorosa.

Consciente de que el amor lejos de ser eterno corresponde a un devenir, la protagonista ahora busca su propio itinerario, a través de un conocerse a sí misma que arroje luz sobre su identidad. Los cuerpos de Diana y Artemisa, como configuración simbólica, le otorgan un andamio para el proceso de autoidentificación. "Con Diana, hacia Diana, a través de la multiplicación y de lo contradictorio, quiere verse en una consonancia, en una conjunción buena. Ella también, ella que escribe, surge, como tantos dioses, de un juego de palabras y de lo que las palabras — pesadas como la matrona de Éfeso, huidizas como la cazadora- muestran y esconden» (150). Del mismo modo en que su escritura conjugaba la fecundidad de Artemisa con la dimensión huidiza de Diana, la protagonista busca su identidad entre ambas figuras, aunque es Diana, en sus múltiples versiones, mo- 
vilidad y contradicciones, quien le señala la vía a seguir: "Pide ser móvil, pide ser sola, y sin embargo se espejea en su hermano menor y rival, un hermano a quien, cuenta la leyenda, ayudó a nacer. Pide ser virgen e intocada, y a la vez sabe que — desgraciadamente- se la invocará de modo desplazado, por analogía mágica entre ella y su madre, como diosa de una fecundidad indolora» (151-152).

Diana, como contrafigura de Artemisa y su sumisión a los roles asignados por el patriarcado, representa la libertad y la autonomía — condiciones sólo otorgadas a los sujetos masculinos- y en su perpetua virginidad ha cancelado toda penetración fálica que, a nivel metafórico, representa la posesión de un otro femenino. La identidad lesbiana se afinca en estas transgresiones sin dejar, sin embargo, de ser mujer, en una genealogía en la cual las mujeres (madre, hermana, amadas) son parte de su cuerpo e identidad.

En la novela En breve cárcel, las aventuras de Diana, la cazadora furtiva, configuran una noción de identidad que implica un constante movimiento y la cancelación de lo fijo como elemento constitutivo de la identidad adscrita. Así, el epígrafe de Virginia Woolf adquiere un doble sentido. Por una parte, alude al «cuarto propio» planteado como las condiciones materiales y sociales que permitirían a las mujeres escribir sus propias experiencias, abriendo una brecha en ese cúmulo de representaciones de la mujer, imaginadas y recicladas por la hegemonía cultural masculina. Al mismo tiempo, la cita «Sola, sin que me vean. [...] Los ojos de los otros son nuestras prisiones; sus pensamientos, nuestras jaulas», aboga precisamente por destruir las cercas de la identidad adscrita.

Coincidiendo con una noción posmoderna de la identidad, también incorporada en la teoría queer, Sylvia Molloy borra los trazos del yo unitario, fijo y totalizante desde una subjetividad lesbiana, que se configura a través de fragmentos heterogéneos (recuerdos de la infancia, sueños, trazos de lo vivido con sus dos amantes) y el constante proceso de desmontar y tachar lo que parecía fijo (Stephenson, 254). De este modo, al final de la novela la identidad resulta ser sólo una de las instancias provisionales de un constante devenir que deparará otras experiencias y otras nociones identitarias. De manera significativa, la protagonista abandona su departamento para viajar a otra ciudad, donde iniciará otros itinerarios. El espacio cerrado del «cuarto propio» ha dejado de ser la morada de una reflexión identitaria que ahora se convirtió en umbral de lo móvil y cambiante (simbolizado por el afuera), del constante desafío de lo desconocido y abierto, como condición de toda identidad provisoria, siempre en situaciones contingentes.

Tomando también el espacio como elemento constitutivo y metafórico de la identidad, Reina Roffé, en El cielo dividido (1996), se enfoca en la otredad, tanto en el sentido de exilio territorial como de una marginalidad con respecto al régimen heterosexual y la nación argentina, tras años de dictadura. Mónica Szurmuk comenta:

En El cielo dividido, el cuerpo femenino está historizado: la contrapartida del placer, de la sexualidad, del erotismo, es la violencia desatada por los militares contra los cuerpos de los opositores. En la ausencia de Giselle y en la presencia de las Madres de Plaza de Mayo, aparecen los cuerpos ausentes, torturados y violentados. Detrás de la tensión entre el papel de amado/a y amante que aparece en la novela en las relaciones de pareja, especialmente la de Mijal y Eleonora, se vislumbra el trasfondo hostil de una sociedad donde las relaciones de afecto y de pasión fueron interrumpidas y penadas (277).

Eleonora regresa a Buenos Aires después de estar casada con Frank en Princeton, para dar «un viraje hacia su verdadero deseo» (Roffé, El cielo dividido, 16). El retorno a su patria no significa, sin embargo, el reencuentro con lo propio, sino una sensación de 
extrañamiento: «Intento dilucidar ese sentimiento, esa idea corrosiva de no pertenecer a nada, a nadie: de estar aquí y allá ajena al tiempo y al espacio» (55). Condición de exilio que hace de ella la encarnación del galut, la diáspora judía de la narrativa bíblica que sólo terminará con la aliá (regreso) y la shejiná, esa presencia divina que se representa de manera no figurativa y sin un género sexual, como reflejo volátil y multiforme que los cabalistas del siglo XIII definieron como espacio andrógino.

La imagen inmóvil de su foto que mantiene bajo el vidrio de la mesa apunta hacia el hermetismo y pasividad de Eleonora y su existencia a la intemperie y en la ambivalencia de un querer pertenecer sin pertenecer. De manera significativa, será su relación amorosa con Mijal la que marque el inicio del cumplimiento de su deseo lesbiano y el descubrimiento de sí misma. No obstante los conflictos teñidos por la rivalidad y el deseo de poder, ambas logran un autoconocimiento identitario: «A solas, tanto Mijal como yo, fuimos, una para la otra, un enigma difícilmente descifrable; y en esto radicaba gran parte de la atracción que sentíamos. Pero a la vez, la pelea contra el desconocimiento nos facilitó desentrañar parte del misterio que cada una era para sí misma» (103).

La luz que desfigura los rasgos de su cara en la foto es el preámbulo de un escribirse a sí misma, de inscribirse en el ancho río de la identidad al cual llegó por Mijal, cuyo nombre en hebreo significa «riachuelo». De esta manera, se da una apropiación de la shejiná, ya no como la luz del regreso al espacio natal, sino como la entrada a un ámbito andrógino, en los bordes de la heterosexualidad, que provee un regreso a lo que siempre fue y se mantuvo silenciado.

Tanto en En breve cárcel como en El cielo dividido, las relaciones lesbianas resultan ser el puente que conduce a la reflexión acerca de la identidad propia. En Tu nombre escrito en el agua (1995), de Irene González Frei ${ }^{1}$, deseo e identidad se entrelazan en una relación no disyuntiva que cancela algunos de los paradigmas del régimen heterosexual. La figura de Narciso y el leitmotiv del doble socavan la noción de sujeto unitario como una totalidad autónoma y, al mismo tiempo, configuran el tópico de la hermandad/pasión amorosa como contratexto lesbiano de una masculinidad heterosexual teñida por la agresión y la violencia. Entretejido en esta elaboración de la identidad, se da un discurso de la sexualidad lesbiana en una reciprocidad que elimina el dualismo de poder entre un sujeto masculino y un otro femenino, que es también objeto de placer. Es más, a diferencia de los otros textos comentados, donde lo sexual se presenta en una explicitez fotográfica (Monte de Venus), de una manera más bien implícita (En breve cárcel, Muñeca rota, Una mujer y cuatro más, El cielo dividido) o en un intento algo fallido de darle una dimensión poética (Amora, 1989 de María Roffiel y Dos mujeres, 1990 de Sara Lévi Calderón), en la novela de González Frei se elabora un imaginario de la sexualidad lesbiana anclado en el mito de Narciso y una detallada topografía del placer lesbiano.

Tu nombre escrito en el agua se inicia con una escena en la cual Santiago mantiene atadas a dos mujeres (Sofía y Marina), mientras las golpea y las viola, haciendo de la casa un espacio de la perversión. Éste es el marco que da paso a los sucesos anteriores en la

Con este seudónimo se presenta el manuscrito al XVII Premio La sonrisa vertical y el fallo del jurado, por primera vez en la historia de este premio, fue unánime. En la contratapa del libro, se dice: «De Irene González Frei sólo sabemos lo que ella misma ha querido revelar hasta ahora en la prensa: es una joven estudiante hispanoamericana afincada temporalmente en Roma, que, por encima de todo, desea seguir escribiendo en la discreción del anonimato». 
narración de Sofía, para volver, al final, a la misma escena que continúa con Santiago, ahora matando a Marina a cuchillazos.

Del mismo modo como la línea temporal se bifurca en un pasado y un presente, a nivel estructural se da la contraposición entre una relación heterosexual y otra lesbiana, creando una línea divisoria entre la pornografía y el erotismo, como señala Ivonne Cuadra. La relación de Sofía con Santiago se elabora como una hipérbole perversa de la sexualidad: el sadomasoquismo, en una práctica de dominación donde el dolor y la humillación son parte del placer. No obstante los roles de lo sádico y lo masoquista se alternan entre uno y otro, ambos personajes siguen encasillados en las categorías normativas de «lo femenino» y «lo masculino». Además, como en otros textos pornográficos, la exhibición del acto sexual se da como un espectáculo corporal, con énfasis en las zonas erógenas y sin trascendencia a nivel amoroso o espiritual.

Esta relación tiene como antecedente un acto de traición a la amistad y «un salvaje deseo de expiación y violencia» (63) que transforma las caricias en maltrato: «el beso que nos dábamos se convirtió en intercambio de babas, en injurias, en dentelladas rencorosas» (63). Dentro de una economía libidinal orientada hacia la penetración fálica, ambos exploran diferentes posturas y martirios, acudiendo incluso a las sogas que atan a Sofía, a los vídeos pornográficos, a un consolador y un tubo de cartón que causa el aborto del primer hijo. El semen, la orina, los vómitos, el sudor y la sangre pasan de elementos naturales a la esfera de lo abyecto en la sexualidad degradante de dos cuerpos, siempre insatisfechos bajo una modalidad heterosexual que no les corresponde. Después del aborto, Sofía y Santiago siguen juntos en una relación donde lo sexual es suplantado por el miedo, el rencor y la violencia reprimida.

La existencia de Sofía sigue, entonces, teñida por una sensación de carencia, de la espera de algo indefinido que va a encontrar en Marina. El espacio vulgar y artificioso de una piscina pública será el escenario de este encuentro:

La piscina tenía la forma de un riñón un tanto deforme. A un lado, entre palmas enanas y peñas grises, había un falso manantial que desembocaba en una falsa cascada, cuyo rumor parecía devolver un poco de silencio al ambiente estorbado por una demasiado fervorosa canción sudamericana. Recorrí un sendero de piedra; esquivé el lavapiés, en cuyas aguas turbias flotaban briznas de hierba seca, un pitillo a medio fumar, escarabajos muertos y un esparadrapo usado (105-106).

Es allí donde ve a Marina, una mujer tan parecida a ella como si fuera su hermana gemela.

Hasta entonces, Sofía se masturbaba frente a un espejo para satisfacer ese deseo no logrado en relaciones heterosexuales. Marina, por lo tanto, transforma el reflejo en un ente real, en la apertura de una reciprocidad amorosa que la rescata de su placer solipcista. Al mirarla desde el bar, Sofía la intuye como una luz: «descubrir a hurtadillas el otro lado de mí misma, el lado diáfano, el que podía librarme de las sombras para conducirme a la luz, a la claridad que nunca había conocido» (112). El cruce del cristal del espejo en epígrafe de Lewis Carroll marca, así, el umbral de una sexualidad lesbiana que provee otros parámetros para la identidad, ahora no fundamentada en la totalidad autónoma y unitaria del sujeto cartesiano, sino en la fusión de dos seres que son uno y dos al mismo tiempo, como se observa en el siguiente pasaje: "La miré a los ojos, y allí vi mis ojos mirándome. Me giré, nos giramos. Nos contemplamos en los rotos reflejos repetidos del agua y fuera de ella, y éramos cuatro Narcisos y uno y dos, nos miraste, me miramos en 
las ondulaciones de la piscina para buscar nuestro rostro verdadero y nuestro nombre escrito en el agua» (118).

Al zambullirse en el agua, la piscina se rearticula, convirtiéndose en el espacio uterino de dos gemelas que, en etapa anterior al lenguaje y la Ley del Padre, se comunican a través de sus cuerpos y la caricia del líquido amniótico. La piscina es también la alcoba del primer encuentro sexual, como un nuevo umbral para la identidad:

Nos abrazamos, y el primer abrazo en esas profundidades infinitamente remotas nos separó del pasado y nos unió, Narciso se abrazó a Narciso, nos estrechamos desaforadamente entre las burbujas del aliento y la espuma de la luz, nos acariciamos bajo el agua hasta el límite último de nuestros pulmones a punto de estallar, y entonces subimos, regresamos otra vez al mundo, pero ya no éramos las mismas, habíamos atravesado nuestro río del olvido, franqueado el umbral de los espejos, perdida la vieja piel, nos habíamos iniciado en los misterios de la identidad que se divide para hallarse (119-120).

La figura de Narciso transgrede el orden represivo de la sexualidad heterosexual con su meta procreativa y revela una nueva visión de la realidad, gobernada por otros principios (Marcuse, 163). El joven que se enamora de su propia imagen en el agua es, al mismo tiempo, sujeto y objeto de su deseo. Si en nuestra cultura siempre se ha dado el rechazo a la similitud para establecer, como parámetro, la disyunción y la diferencia sistematizadas por el falogocentrismo en oposiciones binarias, Narciso y su reflejo en el agua cancela la distinción entre el sujeto y el objeto o el otro, para insertar la categoría de lo mismo, condenada en el mito griego a la muerte.

Llama la atención que haya sido Havelock Ellis quien en 1898 utilizara el término «narcisismo» para referirse a aquellos que hacen del cuerpo propio un objeto del deseo. Desde su perspectiva binarista, tener relaciones sexuales con «el mismo sexo» o ser sujeto y objeto del placer al mismo tiempo, sólo merecía ser catalogado como una anomalía patológica.

En Tu nombre escrito en el agua, las trangresiones de Narciso prefiguran una noción de la sexualidad lesbiana que socava aun otros parámetros de la cultura creada por la voluntad falogocéntrica. Ser uno y dos al mismo tiempo va contra el cómputo y la unidad, fundamentos que desaparecen en la relación de Sofía y Marina: "Tuve la impresión de que nos dábamos un único beso, el mismo que habíamos iniciado en la piscina y que debía durar para siempre» (127). Como ha demostrado la sexología, en términos del orgasmo se da una asimetría entre el del hombre, quien al llegar al punto máximo sigue una línea de declinación, un estado de reposo que requiere de un lapso de tiempo antes de una nueva erección, y el de la mujer, que se puede producir un número indefinido de veces. Multiplicidad que se hace evidente en la relación de estas dos mujeres: «No salíamos de los orgasmos como quien cierra tras de sí una puerta que no volverá a abrir, sino como quien atraviesa laberintos, cuyas galerías no tienen término, o recorre el espacio, el mar, el aire, donde no existen fronteras, no hay principio ni fin, y el itinerario y la meta son la misma cosa» (213). Lo múltiple borra límites y fronteras, demarcaciones clave a nivel del espacio de cada nación y los espacios asignados, tanto en la esfera de lo material como en los diversos saberes que establecen especializaciones en los ámbitos de lo científico, lo técnico y lo humanístico. Del mismo modo, se tacha la noción de principio y fin y esa línea teleológica que ha impuesto un propósito o una meta en la praxis de todo quehacer cultural. 
La eliminación de la asimetría entre la sexualidad masculina y la sexualidad femenina produce en la relación de Sofía y Marina la armonía, la serenidad y el sosiego de un "calmo fervor» (174), de otro tipo de pasión en los bordes de un entorno dominado por la agresión y el utilitarismo de la hegemonía androcéntrica. Y, en este sentido, la refuncionalización del borde de la carretera como espacio erótico apunta hacia esa relación lesbiana que se mantiene en los márgenes y los intersticios de un devenir histórico ordenado a partir de la heterosexualidad y regido por una supremacía masculina.

Por otra parte, los encuentros sexuales de dos mujeres crean una topografía muy diferente a aquella inscrita desde una perspectiva falogocéntrica. Como ha señalado Luce Irigaray: «[...] la mujer tiene órganos sexuales más o menos en todas partes. Ella encuentra placer casi en cualquier parte. Incluso si nos refrenamos de invocar la histerización de todo su cuerpo, la geografía de su placer es mucho más diversificada, más múltiple en sus diferencias, más compleja, más sutil de lo que comúnmente se imagina [...]» (28). En Tu nombre escrito en el agua, el cuerpo, en un discurso disidente de la sexualidad normativa, en vez de ser parcelado en un número limitado de zonas erógenas, es todo en sí sitio del placer. Pluralidad y diversidad que transgrede la noción de la penetración fálica como única meta y culminación de todo acto sexual.

Una vez nos besamos una a la otra, completamente sin dejar nada fuera del alcance de los labios, los dedos de los pies, el sudor de las corvas, los músculos de la espalda, el valle del cuello, las cuencas de las clavículas, las fosas nasales, cada uno de los vellos de la entrepierna, chupándolos uno a uno como joyas delicadas, únicas, las innumerables arrugas de la mano, la barbilla, la larga curva de las costillas (217).

Esta topografía múltiple del placer conduce, a diferencia de la pornografía, al erotismo y la sensualidad de dos cuerpos y dos subjetividades que se unen y trascienden a la esfera del agua primordial, de aquel principio de la vida en su dimensión cósmica, como se observa en el siguiente pasaje:

[...] asomándote a la costa desde el promontorio de tus labios húmedos, y hallabas en el remanso de mis hombros los brazos de mis brazos, que eran tuyos también, una cascada silenciosa, un arroyo que surcabas de abajo a arriba, de arriba abajo, que fluía y desbordaba entre tus piernas, un lago que se volvía torrente entre tus dedos, un chorro claro con que lavar el pasado, crecía, anegaba mis sentidos, y yo timoneaba las velas más profundas de tu coño, del mío, desplegadas al viento, quería vadearte como si me bautizara en ti, arrastrarte a los rápidos más rápidos de mi deseo, hacerle rodar por los desfiladeros de mi ingle, pero tú erigías un suave embalse para detener el curso vertiginoso de mi orgasmo y gozarlo juntas, destilarlo gota a gota, contemplarnos en él, para al fin llevarme hasta el remolino último, la confluencia final, compartida, y entonces poníamos rumbo hacia el oceáno abierto, infinito, hacia la inmensidad Marina (238-239).

A diferencia de los imaginarios de carácter androcéntrico regidos por la heterosexualidad, aquí se anula el binarismo entre un sujeto masculino y otro femenino en una relación de poder que plantea el acto sexual como posesión. Por el contrario, se plantea el erotismo lesbiano como reciprocidad/hermandad, a través de la cual se anula toda territorialización y el imperio de lo propio para entrar a una economía del don. Como establece Hélene Cixous, es precisamente este imperio de lo propio el que ha producido en nuestra cultura la obsesión falogocéntrica por poseer, nombrar y elaborar conceptos, 
en un proceso que siempre implica ordenar y jerarquizar con la consecuente devaluación de uno de los términos (240-249).

Sofía define a Marina como «el espejo perfecto de mi propio deseo y mi propio ser» (187), reflejo viviente que hace posible el amor de Narciso. Esta armonía es tronchada por Santiago, cuando mata a Marina en un impulso vengativo que corresponde al despecho de ya no poseer a Sofía quien, en su narración, le habla a Marina en el tono patético de lo ya perdido para siempre: «¿Y dónde están tus manos, que como la encina me comunicaban las verdades de mi vida por el atajo de tu cuerpo?» (202). En Tu nombre escrito en el agua, el cuerpo amado es el umbral de una identidad lesbiana que no se construye a partir de elucubraciones filosóficas, sino por la vía múltiple de la sexualidad. Desde una jouissance lesbiana más allá del sistema falogocéntrico, Irene González Frei socava no sólo el régimen heterosexual, sino también las nociones de sujeto e identidad. La imposibilidad de un nombre escrito en el agua, según nuestra hegemonía cultural, apunta hacia esa exclusión e invisibilidad del lesbianismo en los discursos e imaginarios prevalentes. Simultáneamente, la elaboración literaria de la experiencia lesbiana crea un discurso y un imaginario que legitiman esta sexualidad, insertando otras alternativas epistemológicas.

La noción de la sexualidad como spectrum mutable y heterogéneo ha servido de base a la teoría queer, término que se refiere a todo aquello que excede y cuestiona las normas heterosexuales, razón por la cual David Córdoba define lo queer no simplemente como la suma de gays, lesbianas, bisexuales, transexuales y otros sujetos aún sin nominación, sino como todo aquello que se aparta de la norma sexual, esté o no articulado en figuras identitarias (22). La transgresión del régimen heterosexual no sólo desestabiliza el binarismo de "lo femenino" y "lo masculino", sino que también pone en jaque el concepto esencialista de la identidad con sus nominaciones fijas y estrictas categorías. Desde esta perspectiva que analiza las relaciones entre práctica sexual, producción identitaria, cultura y nación, se plantea la identidad en una mutabilidad que excede los parámetros hechos legibles por la regimentación hegemónica, exceso que también implica la intersección de identidades múltiples, lo que permite incluir a otros sujetos excluidos, como las minorías étnicas.

A pesar de que el propósito político de la teoría queer intenta desestabilizar las taxonomías heterosexuales, situando a todos los que practican sexualidades alternativas en este grupo disidente, hasta ahora ha persistido una infraestructura genérica de carácter patriarcal que ha otorgado especificidades distintas, tanto a nivel de lo subcultural como en las recientes asociaciones políticas.

En el caso de España, por ejemplo, Beatriz Gimeno afirma que las lesbianas son más discriminadas por ser mujeres que por su preferencia sexual y que en el movimiento LGTB la perspectiva lesbiana representa a una minoría discriminada, razón por la cual declara:

La cultura gay, más valorada social y políticamente y desde luego más fuerte económicamente, se ha impuesto sobre una frágil y escasa cultura lesbiana que corre el peligro de convertirse en una mala copia de aquélla. Dentro del movimiento y de la sociedad gay, las lesbianas se encuentran con que lo masculino es siempre más valorado y tiene más fuerza que la visión o la experiencia que las lesbianas tratamos de hacer llegar a la sociedad. El movimiento homosexual todavía hace referencia a una forma de vivir la sexualidad, el amor, la pareja, el ocio, la vida en sociedad que es claramente masculina. Sus puntos de vista, sus manera de vivir y de relacionarse se han impuesto comunes a gays y lesbianas $[\ldots](22-23)$. 
Esta asimetría genérica de carácter patriarcal se observa también en el hecho de que los lugares de consumo y entretención lesbianos son escasos al comparárselos con aquéllos de los gays; y que éstos, por su mayor solvencia económica, han sido capaces de comprar propiedades y establecer comunidades, mientras las relaciones lesbianas están menos localizadas en la esfera pública (Jays, 163-168). Así, en el caso de Buenos Aires, las lesbianas carecen de los circuitos creados por los gays. Al respecto, Viviana Gorbato señala: «A diferencia de los hombres gay (se calcula que salen alrededor de 15.000 los fines de semana), las lesbianas que frecuentan las discos son la minoría (no superan las quinientas). Las que no concurren a centros culturales, clubes deportivos, o asociaciones militantes prefieren las fiestas en las casas» (80).

La reiteración de una dicotomía espacial y cultural de carácter patriarcal se ha hecho también evidente en la visibilidad y poder de interlocución pública que ha logrado la cultura gay, tanto a nivel comercial como en la literatura, el cine y la televisión. Si bien este fenómeno se explica, en parte, por una mayor agencia y acceso a la producción cultural, convendría investigar más a fondo los factores que dan a la figura del gay atributos aptos para lo espectacular y la farándula televisiva, mientras la lesbiana, considerada opaca y de mal gusto, reitera su invisibilidad. En el caso de la narrativa latinoamericana, en estos últimos años se ha dado un aumento considerable en la publicación de novelas gay, algunas consiguiendo un alto número de ventas, mientras las que se refieren a experiencias lesbianas son aún muy escasas.

Fuera de la órbita oficial de la bien delineada identidad nacional, cultural y genérica, con sus profusos discursos, los textos aquí comentados inscriben en los espacios en blanco los trazos de una identidad propia a partir de la experiencia lesbiana silenciada que se legitima a través de la escritura.

\section{REFERENCIAS}

Butler, Judith. "Imitation and Gender Subordination», The Lesbian and Gay Studies Reader. Ed. H. Abelove, M. Aina Barale y D. M. Halperin. Nueva York: Routledge, 1993, 307-320. Medio impreso.

Córdoba, David. «Teoría queer: Políticas sobre sexo, sexualidad e identidad: Hacia una politización de la identidad», Políticas bolleras, maricas, trans, mestizas. Ed. D. Córdoba, J. Sáez y P. Vidarte. Barcelona: EGALES, 2005, 21-66. Medio impreso.

Cuadra, Ivonne. "Tu nombre escrito en el agua: Hacia una nueva interpretación del sujeto homoerótico». Espéculo: Revista de Estudios Literarios 16 (2000). Revista electrónica. Fecha de ingreso: 10 de agosto de 2011.

Ferreira-Pinto, Cristina. "En breve cárcel: Escribiendo el camino del sujeto", Letras Femeninas 15 (1989), 75-82. Medio impreso.

Geel, María Carolina. El mundo dormido de Yenia. Santiago: Editorial Cultura, 1946. Medio impreso.

. Cárcel de mujeres. Santiago: Editorial Cuarto Propio, 2000. Medio impreso

Giannini, Humberto. La «reflexión» cotidiana: Hacia una arqueología de la experiencia. Santiago: Editorial Universitaria, 1987. Medio impreso. 
Gimeno, Beatriz. "La doble discriminación de las lesbianas». Cultura, Homosexualidad y homofobia, vol. II. Barcelona: Editorial Laertes, 2007. 19-26. Medio impreso.

González Frei, Irene. Tu nombre escrito en el agua. Barcelona: Tusquets Editores, 1995. Medio impreso.

Gorbato, Viviana. Fruta prohibida: Un recorrido revelador por lugares, costumbres, estilos, historias, testimonios y anécdotas de una sexualidad diferente: La cara oculta de la Argentina gay. Buenos Aires: Editorial Atlántida, 1999. Medio impreso.

Grosz, Elizabeth. "Refiguring Lesbian Desire», The Lesbian Posmodern. Ed. Laura Doan. Nueva York: Columbia University Press, 1994. 67-84. Medio impreso.

Jays, Elsie. «Domestic Dykes: The Politics of In-Difference», Queers in Space: Communities/Public Spaces/Sites of Resistance ed. por G. Brent Ingram, A-M Bouthillette e Y. Retter. Seattle: Bay Press, 1997. 163-168. Medio impreso.

Molloy, Sylvia. En breve cárcel. Barcelona: Seix-Barral, 1981. Medio impreso.

Rich, Adrienne. "Compulsory Heterosexuality and Lesbian Existence». Journal of Women's History 15:3 (Otoño 2003). 24-37. Medio impreso.

Roffé, Reina. Monte de Venus. Buenos Aires: Ediciones Corregidor, 1976. Medio impreso.

- La rompiente. Buenos Aires: Punto Sur Editores, 1987. Medio impreso. . El cielo dividido. Buenos Aires: Editorial Sudamericana, 1996. Medio impreso.

Roffiel, Rosa María. Amora. México D.F.: Sentido Contrario, 1989. Medio impreso.

Stephenson, Marcia. "Lesbian Trajectories in Sylvia Molloy's En breve cárcel», MLN 112:2 (1997). 253-268. Medio impreso.

Szurmuk, Mónica. «Entre mujeres: Sexo, pasión y escritura en El cielo dividido de Reina Roffé». Sexualidad y nación. Ed. Daniel Balderston. Pittsburgh: Biblioteca de América, 2000. 271-282. Medio impreso.

Wittig, Monique. "One Is Not Born Woman». The Lesbian and Gay Studies Reader. Ed. M. Abelove, A. Barale y D.M. Halperin. Nueva York: Routledge, 1993. 103-108. Medio impreso.

Wolfe, Maxine. «Invisible Women in Invisible Places: The Production of Sexual Space in Lesbian Bars». Queers in Space: Communities/Public Spaces/Sites of Resistence. Ed. G. Brent Ingram, A-M Bouthillette e Y. Retter. Seattle: Bay Press, 1997. 301-324. Medio impreso. 